\title{
Utility of cinema in medical pedagogy: a novel ideology based on a case study of "apocalypse now"
}

\author{
Ishan Lamba ${ }^{1}$
}

Published online: 4 August 2020

(C) Springer Nature Switzerland AG 2020

\begin{abstract}
The advent of the internet age has impacted every sphere of modern medicine, including medical education. The new generation of trainees require novel approaches to teaching to make the requisite impacts on their minds. Conventional classroom teaching might be considered obsolete by some, especially when the subject being talked about is ethics and philosophy of medicine. An untapped resource for the teachers lies perhaps in the colossal reserve of decades of cinema. This novel concept of using movies to teach is enumerated in this article by using the 1979 film "Apocalypse Now" to draw parallels between the situations occurring in the film with the ethical dilemmas that a clinician might face or philosophies that may be of utility to a physician. This article presents a conceptual framework of this ideology by exploring a film that might be considered by some to have no correlation with the queries that a medical mind might have while proving that it might not be the content of the film but the viewpoint of the teacher/trainee that may define the interpretations that may be drawn from it. Soldiers and doctors both work in a strict structure of hierarchy and are both put in situations where ethical dilemmas have life and death implications. This core philosophy has served as an inspiration for this article.
\end{abstract}

Keywords Cinema $\cdot$ Pedagogy $\cdot$ Apocalypse now $\cdot$ Movies

\section{Background}

Literature has conventionally been defined as a body of writings on a particular subject (Merriam Webster 2020). As times have metamorphosed, this perception has also changed to keep pace with the information highway that has opened up the avenues of digital media and the internet to the entire world at the mere click of a button.

Ishan Lamba

drishanlamba@yahoo.com

1 Department of Emergency Medicine, Dr DY Patil Medical College, Dr DY Patil Vidyapeeth, Pimpri, Pune, Maharashtra 411018, India 
This age of the internet has also bought with it an ease of access to the cinematic art forms which are available for consumption at one's own convenience. It has been argued that a movie's screenplay can be seen as written word by an author (Saeed Zanjani 2008) and fits neatly into the defined parameters of being a piece of literature. Considering the ease of availability and the convenience with which this media can be analyzed, the potential of cinema as a source of philosophical study cannot and should not be discounted. One may also consider the appeal that televised media might hold for the budding physicians and teachers/senior clinicians must consider its usage as a medium to impart soft skills (Lim and Seet 2008).

Cinema has been used for medical teaching for quite a while. A search in the literature revealed that an entire academic journal dedicated to this purpose,by the name of Revista de Medicina y Cine (Journal of Medicine and movies), is being published since 2005 by the University of Salamanca. Senior medical students in Lanari Institute, Buenos Aires are encouraged to participate in a monthly Medicine and Movie program with the intention of teaching professionalism, medical ethics and social justice (Quadrelli et al. 2009). Shapiro and Rucker in their article inspired by Cerventes's work Don Quixote compared a physician learner to the character of Sancho Panza, who cannot be simply exposed to a new data pool but instead needs proper guidance to put it into the right context for him (Shapiro and Rucker 2004).

The entire world, especially the global healthcare industry, are passing through an existential crisis right now. A significant organizational issue that has been highlighted in the recent times is the unpreparedness of our systems to deal with large scale crisis. The Corona virus pandemic has not only displayed cracks, but perhaps crippled the healthcare systems of many countries.

Approaching with this perspective, we hereby present the analysis of the movie "Apocalypse Now" while attempting to draw ethical and philosophical conclusions from it which may translate to bedside medicine and perhaps provide us with novel tools to deal with novel problems.

\section{Introduction}

The 1979 feature film "Apocalypse Now" written and directed by Francis Ford Coppola (Brando 1997) is set in the background of Vietnam war. The story tracks the journey of Captain Benjamin L. Willard from the city of Saigon, Vietnam to an outpost in bordering Cambodia on board a Patrol Boat Riverine (PBR) accompanied by four naval officers. Captain Willard's mission is to assassinate Colonel Walter E. Kurtz, a highly decorated military officer, who is executing his own form of brutal guerilla warfare upon the People's Army of Vietnam (NVA) and the People's Liberation Armed Forces of South Vietnam (PLAF), outside any direction or control from his senior officers (Apocalypse Now 1979).

Seeking inspiration from this storyline and the characters of the film, we draw parallels between the events as they transpired in the film and situations that a clinician may face or experience in their clinical life. 


\section{Captain Benjamin L. Willard as a model for physician burnout}

Captain Willard is portrayed as a disillusioned officer who is currently on his second tour of Vietnam (Apocalypse Now 1979). It is depicted that because of his experiences in the battlefield he seems to be suffering from posttraumatic stress disorder (PTSD) as suggested by his:

(a) inability to maintain his relationship with his wife.

(b) alcoholism.

(c) substance abuse (cigarette, opium)

(d) tendency towards self harm.

An officer suffering from PTSD is in many ways similar to a physician experiencing burnout in the sense that both have been subjected to "moral injury" (Talbot and Dean 2018; Litz et al. 2009). Physician burnout (PBO), while not a recognized psychological disorder, is a widely recognized condition plaguing the mental health of physicians worldwide (Shanafelt et al. 2017; West et al. 2016, 2018). A number of studies have drawn parallels between PBO and PTSD (Jackson et al. 2019; Wapperom 2016; Jackson et al. 2017). These studies have found a significant overlap in the symptomology of PBO and PTSD, suggesting that physicians working in stressful environments that require constant decision making, both medical and ethical in nature, are subject to the similar risk of deterioration in mental health that soldiers in wartime situations are.

\section{Maladaptive coping}

"Everyone gets everything he wants. I wanted a mission, and for my sins, they gave me one. "(Apocalypse Now 1979) This statement by Captain Willard mirrors the avoidance method applied by many clinicians as a maladaptive coping mechanism to tackle burnout (Bittner et al. 2011). The Captain is not in the psychological frame of mind to go back into the field. Yet he thinks that a mission is what he needs to distract him from his problems.

Similarly, physicians ignore their own needs for optimum mental health and continue to burden themselves with more work (King et al. 1992). It has been demonstrated that most clinicians choose one of the following coping mechanisms:

(a) Keeping one's emotions to oneself.

(b) Focusing on the next task at hand.

(c) Going on as if nothing happened.

These are classical examples of maladaptive coping which place the clinician in a vicious cycle of stress and have been positively correlated with emotional exhaustion (Lemaire and Wallace 2010).

\section{Maintaining doctor-patient confidentiality}

When Colonel G. Lucas subjects Captain Willard to a line of enquiries regarding his past missions, the Captain denies any knowledge whatsoever of the said incidences, 
despite it being adequately clear that all the present parties are aware about the facts of these covert operations (Apocalypse Now 1979). This exemplifies his unfaltering ability to maintain professional confidentiality.

Doctor-patient confidentiality is the foundation on which the rapport of a clinician with his patient is laid upon. It is the sanctum santorum of the relationship between a physician and the patient.

It may be necessary under certain circumstances for a doctor to breach confidentiality but what is important for a responsible clinician is to be unmistakably aware about those exceptional circumstances (Dickens and Cook 2000). A novel threat to confidentiality has risen from the realms of social networking.

Studies indicate that the younger generation of clinicians who are active on online networks, tend to divulge information that might add to the patient's suffering or might be considered to be outside the boundaries of ethical practice (MacDonald et al. 2010). It is important for clinicians to weigh their words and opinions before expressing them on any forum for they may have far reaching consequences upon their patient's quality of life and also upon the perception that their colleagues might hold about them.

\section{Risk stratification, team safety and leadership in the workplace}

Lieutenant Colonel William "Bill" Kilgore's persistence upon surfing at a war torn beach amid active shelling (Shapiro and Rucker 2004) displayed heroism crossing over into irrationality and lack of concern for the safety of the men under his command.

Risk stratification is a skill set that many clinicians need to exercise in their daily practice, especially if they are working with patients requiring critical care (Haaf et al. 2017; Plos one staff 2015; Läll et al. 2017). It is the clinician's responsibility to make the appropriate decisions based on a precise risk analysis to assure optimum usage of resources and best outcome for the patients (Martin et al. 2008; Foster et al. 2014).

The other side of the coin is the quality of risk taking which has to be carefully demarcated away from being callous. One has to have decisive clarity to differentiate between the necessary risk- which is based in objective facts and may lead to finer results and unnecessary risks- which may stem from subjective preferences and might not have enough evidence to back them up (Hillson and Doctor 2011).

The irrationality of Colonel Kilgore's behavior may even be linked to the psychological stress that the battlefront might have built up inside him. The same tendency has been noted in clinicians, who when put under the physical and psychological stress, displayed an increased risk taking behavior which affected their decision making skills both in their personal and professional lives (Capanna et al. 2017).

\section{Transparent communication to build mutual trust}

During the journey upriver, for a long duration, Captain Willard does not disclose the final destination to Chief Petty Officer George Phillips. This remains a constant source of disagreement between the two till Captain Willard chooses to share this information with Chief Phillips (Apocalypse Now 1979).

Effective and transparent communication is of paramount importance between all members of the treating team. Poor communication leads to poor team dynamics which eventually negatively impact the quality of care that the patient receives (Handberg and 
Voss 2018). Effective communication amongst various healthcare providers, without breaching confidentiality, is the one of the fundamental requirements for providing quality healthcare.

\section{Careful deliberation before executing decisions}

When the team encounters a Vietnamese civilian boat during their journey, as part of standard operating procedure (SOP), they initiate a search on the same. The junior officers have clearly amassed a lot of anxiety by this point which results in them erroneously shooting down innocent civilians (Apocalypse Now 1979).

SOPs are created to decrease the heuristic approach to decision making and hence decreasing the potential mistakes that might infect the process (Amare 2012). The guidelines are themselves an evolving entity which may change in the future but adhering to the contemporary guidelines is always the safest and the most resource efficient methodology while wavering from them might lead to negative consequences, both for the patient and the physician.

\section{Save what you can: triage \& euthanasia}

After the preceding shootout, one of the civilian women is surviving. Chief Phillip's suggestion is that as per the SOPs the woman should be escorted to the nearest medical facility. Captain Willard expresses his disagreement with the recommendation and as the conversation degenerates into an argument between the two, Captain Willard puts an end to the conversation by shooting and killing the woman (Apocalypse Now 1979).

Triage encompasses some of the toughest decisions that a clinician has to make on the floor. The decisions taken by the physician which take into account the patient's overall condition, the available resources and the possible prognosis, can translate into life and death scenarios and hence are not only notoriously complicated but also may be ridden with controversy (Repine et al. 2005). The decisions regarding triage push the boundaries of the ethical frontiers and test not only the clinician's knowledge but also his resolve. Guidelines and models for emergency triage have been recommended, (Aacharya et al. 2011) but the stark reality remains that it is the clarity of the treating physician's mindset that would be the pivotal decision making tool in the entire process. The clinician should have a flawless idea about the available resources, departmental priorities, and ethics of good practice. He/she should be able to strike the perfect balance between all these determinants and arrive at a conclusion that is in patient's best interest.

The instance of shooting the woman by Captain Willard can also be utilized to reflect upon the highly controversial and evolving realm of euthanasia. Euthanasia, while in its final form is a medical decision, has its roots planted deeply into our individual religious, social, familial and personal values (Lee et al. 2019). Although it has been made legal in a small number of countries, the ethical concerns hinder its acceptance in vast sections of society.

(Author would like to add at this point that in no way do they condone Captain Willard's action in the circumstances as they were outside the bounds of humanitarianism and ethics.) 


\section{Substance abuse among physicians}

Soon after the civilian shootout, Gunner's mate Lance B. Johnson admits to Engineman Jay "Chef" Hicks that he consumed the last tablet of acid (Lysergic acid diethylamide) that "he had been saving"(Apocalypse Now 1979). This points to recreational drug use while on mission, behind enemy lines, under circumstances of extreme psychological stress.

Substance abuse is not a problem that the medical fraternity is untouched by. There is a direct correlation between PBO and substance abuse, perhaps leading to a vicious cycle of one fuelling the other (Forster 2017). Beyond the personal and professional damage that such habits might cause to the clinician, there is a threat of fraud and legal consequences that the employee's organization might be subject to as a result of this (Millar et al. 2019). This vicious cycle of occupational stress and substance abuse also leads to deterioration of the quality of healthcare provided and hence early recognition and intervention can prevent damaging consequences to the physician, patients and the organization (Medisauskaite and Kamau 2019).

\section{Conclusion}

This case study serves as a conceptual framework to view a movie as a device to draw parallels which may be utility to doctors and medical students. A change in perspective while viewing conventional cinema can provide valuable insights that may be used to gain insights into professional dilemmas and might even be of some utility to impart ethical lessons to medical students.

There are a number of articles which have enumerated the symbiotic relationship between fictional literature and clinical medicine (Trautmann 1982a, b; Charon et al. 1995). It is perhaps time for us to look towards the silver screen for inspiration to reach out to the millennial generation. The area is not unexplored as has been exemplified by the works of Mejia (2019) and D'Ottavio et al. (2019).

Apocalypse now, inspired by Joseph Conrad's novella Hearts of Darkness, may be considered a peculiar choice to demonstrate the utility of cinema as a medical teaching tool. But as has been enumerated in this article, soldiers and doctors share many occupational commonalities. They both are expected to work in strict systems of hierarchy which are bound by laws and ethics. Military personnel and healthcare providers both face ethical dilemmas which may have life and death implications. They both are subject to psychological turmoil as occupational hazards. This core philosophy has served as an inspiration for drawing this parallel.

Films based on the field of medicine can be put into the clinical context rather conveniently. This case study has purposely been designed around such a movie which is outside the purview of the subject of medicine to prove the point that there is no dearth of sources of inspiration beyond the conventional means of teaching. The teacher's viewpoint can define both the source and the direction of teaching.

\section{Compliance with ethical standards}

\section{Conflict of interest There is no conflict of interest.}




\section{References}

Aacharya, R.P., C. Gastmans, and Y. Denier. 2011. Emergency department triage: An ethical analysis. BMC emergency medicine. 11 (1): 16.

Amare G. Review Reviewing the values of a stabdard operating procedure. Ethiopian Journal of Health Sciences. 2012;22(3).

Apocalypse now. Omni-Zoetrope; 1979.

Bittner, J.G., IV, Z. Khan, M. Babu, and O. Hamed. 2011. Stress, burnout, and maladaptive coping. Bulletin of the American College of Surgeons 96 (8): 17-22.

Brando M. Francis ford Coppola presents apocalypse now. Paramount; 1997.

Capanna, M., R. Hou, M. Garner, H.M. Yuen, and C. Hill. 2017. Risk-taking in junior doctors working night shifts in intensive care. Intensive care medicine. 43 (5): 709-710.

Charon, R., J.T. Banks, J.E. Connelly, A.H. Hawkins, K.M. Hunter, A.H. Jones, M. Montello, and S. Poirier. 1995. Literature and medicine: Contributions to clinical practice. Annals of Internal Medicine 122: 599606.

Dickens, B.M., and R.J. Cook. 2000. Law and ethics in conflict over confidentiality? International Journal of Gynecology \& Obstetrics 70 (3): 385-391.

D'Ottavio, A.E., J.E. Sánchez, and E.G. Sánchez. 2019. The cinema as a fostering tool for health area undergraduates. Revista de Medicina y Cine. 15 (2): 101-105.

Forster K. NHS doctors turning to substance abuse amid rising levels of stress and burnout. Independent [Internet]. 2017 Jun 24 [cited 2020 April 28]. Available from: https://www.independent.co. uk/news/health/nhs-doctors-substance-abuse-stress-burnout-rising-gps-addiction-health-service-bmaclare-gerada-a7805571.html

Foster, N.E., R. Mullis, J.C. Hill, M. Lewis, D.G. Whitehurst, C. Doyle, K. Konstantinou, C. Main, S. Somerville, G. Sowden, and S. Wathall. 2014. Effect of stratified care for low Back pain in family practice (IMPaCT Back): A prospective population-based sequential comparison. The Annals of Family Medicine. 12 (2): 102-111.

Handberg, C., and A.K. Voss. 2018. Implementing augmentative and alternative communication in critical care settings: Perspectives of healthcare professionals. Journal of clinical nursing. 27 (1-2): 102-114.

Hillson D, Doctor R. Shedding Light on Risk Appetite: Using risk appetite and risk attitude to support appropriate risk-taking. Risk Doctor \& Lucidus Consulting. Retrieved from http://www.risk-doctor. com/docs/Risk\%20Doctor-Lucidus\%20white\%20paper. 2011.

Jackson, T.N., J.P. Morgan, D.L. Jackson, T.R. Cook, K. McLean, V. Agrawal, K.E. Taubman, and M.S. Truitt. 2019. The crossroads of posttraumatic stress disorder and physician burnout: A national review of United States trauma and nontrauma surgeons. The American Surgeon. 85 (2): 127-135.

Jackson, T., A. Provencio, K. Bentley-Kumar, C. Pearcy, T. Cook, K. McLean, J. Morgan, Y. Haque, V. Agrawal, B. Bankhead-Kendall, and K. Taubman. 2017. PTSD and surgical residents: Everybody hurts... sometimes. The American Journal of Surgery. 214 (6): 1118-1124.

King, M.B., A. Cockcroft, and C. Gooch. 1992. Emotional distress in doctors: Sources, effects and help sought. Journal of the Royal Society of Medicine 85 (10): 605-608.

Läll, K., R. Mägi, A. Morris, A. Metspalu, and K. Fischer. 2017. Personalized risk prediction for type 2 diabetes: The potential of genetic risk scores. Genetics in Medicine 19 (3): 322-329.

Lee, H.J., J.S. Kim, H. Kim, and C.T. Kim. 2019. The awareness of medical department students about euthanasia. The Korean Journal of Emergency Medical Services. 23 (1): 165-178.

Lemaire, J.B., and J.E. Wallace. 2010. Not all coping strategies are created equal: A mixed methods study exploring physicians' self reported coping strategies. BMC health services research. 10 (1): 208.

Lim, E.C., and R.C. Seet. 2008. In-house medical education: Redefining tele-education. Teaching and learning in medicine. 20 (2): 193-195.

Literature [Internet]. 2020 [cited 21 April 2020]. Available from: https:/www.merriam-webster. com/dictionary/literature

Litz, B.T., N. Stein, E. Delaney, L. Lebowitz, W.P. Nash, C. Silva, and S. Maguen. 2009. Moral injury and moral repair in war veterans: A preliminary model and intervention strategy. Clinical psychology review. 29 (8): 695-706.

MacDonald, J., S. Sohn, and P. Ellis. 2010. Privacy, professionalism and Facebook: A dilemma for young doctors. Medical education. 44 (8): 805-813.

Martin, B.I., R.A. Deyo, S.K. Mirza, J.A. Turner, B.A. Comstock, W. Hollingworth, and S.D. Sullivan. 2008. Expenditures and health status among adults with back and neck problems. Jama. 299 (6): 656-664. 
Medisauskaite, A., and C. Kamau. 2019. Does occupational distress raise the risk of alcohol use, binge-eating, ill health and sleep problems among medical doctors? A UK cross-sectional study. BMJ Open 9 (5): e027362.

Mejía-Rivera OR. Literature and cinema in the training of doctors and medical humanities. Acta Medica Colombiana. 2019;44(3).

Millar M, White RM, Zheng X. Substance Abuse and Workplace Fraud: Evidence from Physicians. Available at SSRN 3147938. 2019.

PLOS ONE Staff. 2015. Correction: Risk Prediction of Emergency Department Revisit 30 Days Post Discharge: A Prospective Study. PloS one 10 (1): e0117633.

Quadrelli, S., H.G. Colt, and G. Semeniuk. 2009. Appreciation of the aesthetic: A new dimension for a medicine and movies program. Family Medicine 41 (5): 316-318.

Repine, T.B., P. Lisagor, and D.J. Cohen. 2005. The dynamics and ethics of triage: Rationing care in hard times. Military Medicine. 170 (6): 505-509.

Saeed Zanjani A. 2008. Screenplay: movie script or literature (Doctoral dissertation, Université du Québec à Montréal).

Shanafelt, T.D., L.N. Dyrbye, and C.P. West. 2017. Addressing physician burnout: The way forward. Jama. 317 (9): 901-902.

Shapiro, J., and L. Rucker. 2004. The Don Quixote Effect: Why Going to the Movies Can Help Develop Empathy and Altruism in Medical Students and Residents. Families, Systems, \& Health 22 (4): 445.

Talbot SG, Dean W. Physicians aren't ‘burning out.'They're suffering from moral injury. Stat. 2018 Jul 26.

ten Haaf K, Jeon J, Tammemägi MC, Han SS, Kong CY, Plevritis SK, Feuer EJ, de Koning HJ, Steyerberg EW, Meza R. Risk prediction models for selection of lung cancer screening candidates: a retrospective validation study. PLoS medicine. 2017;14(4).

Trautmann, J. 1982a. The wonders of literature in medical education. Journal of Continuing Education in the Health Professions. 2 (3): 23-31.

Trautmann, J. 1982b. Can we resurrect Apollo? Literature and Medicine. 1 (1): 1-8.

Wapperom A. BURNOUT-A RISK FACTOR FOR DEVELOPING PTSD? (Master's thesis) (2016).

West, C.P., L.N. Dyrbye, P.J. Erwin, and T.D. Shanafelt. 2016. Interventions to prevent and reduce physician burnout: A systematic review and meta-analysis. Lancet. 388 (10057): 2272-2281.

West, C.P., L.N. Dyrbye, and T.D. Shanafelt. 2018. Physician burnout: Contributors, consequences and solutions. Journal of Internal Medicine 283 (6): 516-529.

Publisher's note Springer Nature remains neutral with regard to jurisdictional claims in published maps and institutional affiliations. 